\title{
A Message from BHAC Board President Enhancing our Mental Health by Improving our EQ
}

We had such a terrific biannual virtual 2021 BHAC Summit with terrific presentations from our speakers, which emphasized the building of mental health resiliency. Healthcare claims have increased three and four fold for depression and anxiety during the year of the COVID-19 pandemic. So many other people are languishing right now, which is neither a state of depression or thriving. As such, there has never been a more pressing time to equip our students, faculty and staff with skills to enhance their mental well-being.

If you are one of those people who are languishing right now, it is normal and one way to combat it is with flow. Choose one meaningful task to accomplish each morning and focus on accomplishing it. Small wins help to establish flow as well as help with engagement and productivity.

We also can grow our emotional intelligence (EQ) and be on our way to great relationships and more fulfilling lives. Emotions affect our friendships, our moods, our workspace, our families and, let's be honest, everything we do. The wonderful thing about emotions is that we can learn more about them and grow our own emotional intelligence.

Travis Bradberry and Jean Greaves, authors of Emotional Intelligence 2.0, describe four components of emotional intelligence: self-awareness, self-management, social awareness and relationship management. Unlike personality traits, these are skills we can build and improve upon all of our lives.

\section{Become self-aware}

- Build a strong emotional vocabulary. There are hundreds of words to describe the subtle shades of our feelings. Are we elated, happy or content? Agitated, aggravated or disgruntled? We can learn new words to describe our feelings and practice writing about how we feel in a journal. A strong emotional vocabulary will allow us to identify how we are really feeling and talk about it with someone else.

- Learn our triggers. If we know what sets us off, we can see challenges coming and deal with the emotions that follow. The things that tend to really get us upset are based on our fears — of not being safe or treated fairly, for instance. We can identify situations in our work and personal lives that lead us to feel threatened or uncomfortable and strategize proactively on how to deal with them.

- Sit with our emotions. Rather than label emotions "good" or "bad," we can practice just observing them. How long do they last? Can we name them and let them go? If we need to, we can distract ourselves with deep breathing, a short walk, a glass of water — anything to give ourselves time to cool down and think.

- Take a personality test. This can help us learn our communication style. We all have different ways of expressing ourselves. A personality test such as DiSC or Myers-Briggs can give us more insight into our tendencies and how we might be presenting ourselves to others.

\section{Self-manage our emotions}

- Practice mindfulness. When possible, we can ground ourselves in the present moment without worrying about tomorrow or feeling regret for the past, which are the two most wasted emotions. 
- Catch, check and change our thoughts. When we feel stressed, anxious, depressed or angry, we can catch negative thoughts and check them by asking: What was just going through my mind? Is it true? Do I have evidence to back it up? Is this thinking helpful? Chances are, those negative thoughts aren't helpful. If we turn them around, we'll feel better.

- Get curious. When we feel frustrated or when unexpected occurrences trigger a negative emotional response, curiosity can help us see new possibilities for our response.

- HALT: This acronym from the recovery community urges us to pay extra attention to our emotional reactions when we are hungry, angry, lonely or tired - HALT for short. If we are experiencing more than one of these at a time, it might be best to halt what we're doing and rest!

- Sleep on it: It's often best to put aside big problems until the morning. Also, we need to make sure we are getting enough sleep so we can feel our best: 7-9 hours a night is recommended for adults.

3. Become socially aware

- Show you care: Take the time to ask people how they are doing and what's going on in their lives — both at work and at home. Then listen.

- Check-in regularly: We might think a co-worker is angry with us when, in fact, he is only tired. Or we might think our team is happy with a plan when secretly they are anxious. We should check in with our partners to see what they really feel and allow them to express their feelings in a safe space where they feel free to speak.

- See it their way: We can try to step into others' shoes to see things from their perspective.

4. Work on our relationships

- Practice giving and taking feedback well. If someone gives us honest feedback, we should thank them for it, then pause long enough to control how we respond to it without reacting. We can make our own feedback direct and constructive. When giving feedback, we should do so like an Oreo cookie — say something positive about the person, give the constructive feedback and finish with a positive.

- Adopt a "learner" mindset rather than a "judger" mindset: In challenging situations, we can try to learn more about what others are thinking, feeling and wanting, rather than passing judgment.

Emotional intelligence is about showing up in the world the way we want so we can build strong relationships and have positive and meaningful interactions with others. These are skills we can all practice, and research shows they lead to a happier more fulfilling life.

We truly have had a character-building year. Remember to take your daily dose of Vitamin G-for gratitude. It is one of the briefest evidence-based practices that when practiced daily, can so improve your mood and decrease your stress. I am so grateful for all that you do to take care of people's health and well-being. However, please do not forget to take good self-care as you cannot pour from an empty cup. Rainbows follow rain, and we have a lot of rainbows in store as the pandemic winds down.

Best wishes and stay well!

Fond regards, Bernadette Mazurek Melnyk, PhD, APRN-CNP, FNAP, FAAN 
President and Founder, the National Consortium for BHAC

Vice President for Health Promotion

University Chief Wellness Officer

Dean and Helene Fuld Health Trust Professor of Evidence-based Practice, College of Nursing

Professor of Pediatrics and Psychiatry, College of Medicine

Executive Director, the Helene Fuld Health Trust National Institute for Evidence-based Practice

The Ohio State University 